\title{
LUDWIG TIECK, LECTOR DE FICHTE: SOBRE LAS HAZAÑAS DEL YO
}

LUDWIG TIECK, READER OF FICHTE: ON THE FEATS OF THE SELF

\author{
Ana Carrasco Conde
}

\begin{abstract}
RESUMEN
El artículo analiza los elementos "fichteanos" en la lectura que Tieck hace del Quijote para su traducción (1799-1801), así como la influencia real que Fichte pudo tener en Tieck y que se hace notar no sólo en la forma de entender las hazañas de Don Quijote, sino también — como inversión - en el cuento Der Runenberg (1802) en torno al tema de la locura, la pérdida de control y la conciencia del Yo, que tanta importancia y tanta profundidad alcanzarán al final del Idealismo y del Romanticismo y que toma justamente la imagen del Yo y el poder del No-Yo.
\end{abstract}

PALABRAS CLAVE. Tieck, Fichte, hazaña, Tathandlung, Quijote, Yo.

\section{ABSTRACT}

The article analyzes the elements from Fichte in the reading that Tieck does of the Quixote for its translation (1799-1801), as well as the real influence that Fichte could have in Tieck which can be noticed not only in the way of understanding Don Quijote's feats, but also in the story Der Runenberg (1802) around the topic of the madness, the paranoia and the conscience of the Self, that so much importance and so much depth will reach at the end of the Idealism and the Romanticism, and precisely takes the image of the I and the power of Not-I.

KEYWORDS: Tieck, Fichte, feat, Tathandlung, Quixote, I.

De seguir a Ortega y Gasset en las Meditaciones del Escorial, le debemos a Hermann Cohen la observación con la que iniciamos nuestro texto: tras una conversación acerca del género de la novela, cuenta Ortega que Cohen decidió volver a leer El Quijote y cuando así lo hizo se percató de algo bien llamativo: que Sancho Panza para referirse a los actos heroicos del Caballero de la Triste 
Figura empleaba siempre la misma palabra con la que Fichte había fundamentado su filosofía: Tathandlung (Ortega y Gasset 1983, p. 559). Por ese comentario, que tiene hondas implicaciones en la lectura fichteana que Ortega hace del Quijote (cfr. Ortega y Gasset 2004, pp. 285 y ss), sabemos que Cohen estaba leyendo la traducción de Ludwig Tieck que había empleado este neologismo fichteano para verter el término "hazaña" (Cervantes 1799-1801)1. Aunque esta anécdota es bien conocida, no lo son tanto las circunstancias que rodearon a esta traducción aparecida entre 1799 y 1801 en Berlin bajo el encargo de Friedrich Gottlieb Unger, aunque parcialmente realizada en Jena y que, en un principio, iba a ser acometida por Friedrich Schlegel (Neumann 2004, p. 83)², quien decidió, finalmente pasar la tarea a Ludwig Tieck. Le unía a él una gran amistad basada, sobre todo, en la pertenencia a una misma sensibilidad, la romántica, y con quien compartía un mismo planteamiento con respecto a la labor de la literatura, en relación con los inteses nacionales de la misma, de la creación y de la imaginación. Nos encontramos, pues, ante una traducción realizada en Jena en torno a 1800 y en los círculos de los Schlegel, lo que quiere decir, en los círculos de la Frübromantik, en un periodo de cambio entre épocas: de la Jena de Fichte (1794-1799) a la Jena schellinguiana de la Naturphilosophie (1799-1803), un cambio que tendrá, por otro lado, relevancia para comprender la evolución de la obra del propio Tieck: de un "fichteanismo romántico", a través de la asimilación de algunos de los planteamientos de Fichte mediante la mediación e influencia de los Schlegel, a un "romanticismo traspasado por la Naturphilosophie" por la vía de Henrik Steffens, relacionado sobre todo — muy schellinguianamente - con una naturaleza fundamental, recóndita y amenazante, que no puede ser domesticada. ${ }^{3} \mathrm{El}$ propio Novalis menciona la traducción del Quijote encargada a Tieck a Carolina Schlegel (que por estos mismos años dejará a A.W. Schlegel para contraer segundas nupcias con Schelling), que se espera con mucha impaciencia en el círculo romántico (Novalis 1975, pp. 274-276). ${ }^{4}$

\footnotetext{
${ }^{1}$ El título de la traducción de Ludwig Tieck responde a Leben und Taten des scharfsinnigen Edlen Don Quixote von la Mancha, J. F. Unger, Berlin, 1799-1801, 4 vols. Se encuentra disponible online la primera edición de 1799 en <http:/ / reader.digitale-sammlungen.de/de/fs1/object/ display/bsb10608638_00005.html $>$ [consultado el 1 de septiembre de 2015]

${ }^{2}$ Carta de Fr. Schlegel a A.W. Schlegel del 31 de octubre de 1797.

${ }^{3}$ Puede consultarse el clásico de Danton, G. H. (1907): The Nature sense in the writing of Ludwig Tieck, Nueva York: Columbia University.

${ }^{4}$ Carta de Novalis a Caroline Michaelis-Bohmer-Schlegel-Schelling, 20. Enero de 1799.
} 
Efectivamente en 1799 Fichte debe abandonar su cátedra — y Jena— como consecuencia de la nefasta Atheismusstreit', aunque el núcleo de la Frübromantike, con los Schlegel y Schelling, sigue muy activo, y con él permanece viva una comprensión de la filosofía marcada decisivamente por Fichte: no en vano, durante muchos años -recordemos la carta de Hölderlin a Neuffer en noviembre de 1794- Fichte fue "el alma de Jena": "¡Y por Dios que lo es verdaderamente! No conozco a otro hombre de tamaña hondura y energía espiritual — escribe Hölderlin — Le escucho todos los días" (Hölderlin 1990, p. 214). Filosofar se identificaba en aquellos días con un donoso neologismo de cuño romántico: fichtieren (Fuchs 1980, p. 432). La "revolución fichteana" había alimentado los deseos de cambio de toda una generación con la publicación en 1794-1795 de la Grundlage der gesammten Wissenchaftslebre (Basamento de la entera doctrina de la ciencia), en la que el Yo, identificado como actividad — y actividad libre—, habría superado a la filosofía anterior y en la que la Grundriss des Eigenthümlichen der Wissenschaftslehre (1975), las dos Introducciones a la Doctrina de la Ciencia (1797) y El sistema de la Doctrina de las costumbres (la conocida como Sittenlehre), de 1798, ya habían calado profundamente. Son los años también de puesta en marcha del Athenäum (1798-1800), aunque sabemos que ni Tieck ni Schelling, por ejemplo, contribuyeron en ninguno de los seis números que llegaron a publicarse. De hecho es preciso destacar que, según recoge su biógrafo Köpke, Tieck nunca se sintió parte del grupo (Köpke, 1855, p. 14).

Fue en el mismo año de 1799, tras la muerte de su gran amigo Wackenroder y ante ciertas intrigas con los círculos más Ilustrados del Berlín de la época, cuando Tieck trasladó su domicilio a Jena donde participó asiduamente en las reuniones consagradas al Symphilosophieren en la que intervenían con regularidad los hermanos Schlegel, Novalis, Schleiermacher, Brentano, Ritter y Schelling (que había llegado a Jena en 1798 gracias a los buenos oficios de Goethe), todos ellos dentro de una atmósfera fichteana. ${ }^{6}$ Recuérdese el conocido fragmento 216 del Athenäum en el que la Revolución Francesa, el Wilhelm Meister de Goethe y la Wissenschaftslehre

\footnotetext{
${ }^{5}$ Sobre la polémica sobre el ateísmo en Fichte, más allá de su origen en la Pantheismusstreit iniciada por Jacobi en 1785, de entre la muy abundante bibliografía remito al libro en castellano: Rivera de Rosales, J. y Cubo, O. (eds.) (2009): La polémica sobre el ateísmo. Fichte y su época, Madrid: Dykinson.; y al editado por Kodalle, K.-M. (1999): Fichtes Entlassung: der Atheismusstreit vor 200 Jahren, Würzburg: Königshausen\&Neumann.

${ }^{6}$ Sobre la figura de Ludwig Tieck pueden consultarse Zeydel, E.H. (1971): Ludwig Tieck, the German Romanticist. A critical study, New York: Georg Olms Verlag; Gürzel, K. (1986): König der Romantik: das Leben des Dichters Ludwig Tieck in Briefen, Selbstzengnissen und Berichten, Berlin: Wunderlich; Paulin, R. (1982): A literary biography, Oxford: Clarendon Press.
} 
de Fichte se identifican como las grandes tendencias de su época (F. Schlegel 1967, p. 198). ${ }^{7}$ Con Schelling y Fichte mantiene Tieck una relación cercana, hasta el punto de que este último le pone en contacto con el editor Cotta en un año, 1800, que no es fácil para él a causa de la ya mencionada Atheismusstreit. Ya antes, en 1797, Tieck había entrado en contacto estrecho con los Schlegel, lo que le valió ser considerado como uno de los escritores representativos del primer romanticismo. A través de los Schlegel, Tieck llegaría a Fichte.

Finalmente, 1799 fue el año, como ya hemos hecho notar, en el que Tieck comenzó su traducción de El Quijote. En este contexto el ambiente en el que vivía y pensaba Tieck era completamente fichteano. Si Tieck toma el concepto de Tathandlung no es porque, en el fondo, Fichte exigiera que el Yo para tomar conciencia de sí debía sumirse en una odisea quijotesca de aventuras, sino al revés porque los obstáculos (Hindernisse) que había de vencer Don Alonso Quijano quizá tendrían que ver con una resistencia (Widerstand) puesta (imaginada) por su propio Yo. Esta lectura, es, sin embargo demasiado fácil. El empleo del término fichteano implica, por un lado, que Tieck era conocedor de la obra de Fichte y, por otro, conlleva que ha realizado una lectura comprensiva de la misma y una asimilación —y reformulación— de planteamientos (Markert 2004, p. 155).

En lo que sigue me gustaría ahondar en el porqué de la elección del término Tathandlung y en qué sentido podemos leer las "hazañas" del Yo en la traducción de Tieck, planteando de este modo una lectura fichteano-romántica del Quijote, a la sombra de la Doctrina de la Ciencia; finalmente apuntaré algunas influencias fichteanas en la propia obra de Tieck en torno a estos años. Para ello vertebraré mi texto en tres partes: la primera, "Las hazañas del Yo", estará consagrada a analizar qué sea algo así como la hazaña à la Tieck en relación con lo que implica la Tathandlung para el romanticismo (con atención al Quijote); la segunda, "El proyecto del Quijote" versará sobre el papel de la imaginación en torno a las "locuras" del Caballero andante; finalmente, en la tercera parte "El No-Yo del Yo y la desfundamentación del mundo", esquemáticamente apuntaré algunas consecuencias de la Tathandlung, especialmente focalizándome en Der Runenberg (1802), en el que podemos encontrar una "vuelta de tuerca" al movimiento de reflexividad por la cual el Yo vuelve o regresa (zurückgehen) sobre sí hasta consumar una transformación de la Grundlage fichteana.

\footnotetext{
${ }^{7}$ Sobre la relación entre Fichte, Schlegel y la estética romántica véase el artículo de Radrizzani, I. (1996): “Génese de l'esthétique romantique: De la pensée transcendentale de Fichte à la poésie transcendentale de Schlegel" en Revue de Métaphysique et de morale, n 4, pp. 471-498.
} 


\section{LAS HAZAÑAS DEL YO}

August W. Schlegel anunció la traducción de Tieck en la Allgemeine Literatur Zeitung, del 17 de enero de 1798, como la primera que vertía íntegramente al alemán la obra de Cervantes, y la recomendó, por sugerencia de Friedrich y del propio Tieck, a todos “los amigos del arte romántico”. De hecho, un poco más tarde, A.W. Schlegel diría que El Quijote era "una obra maestra del más elevado arte romántico" (A. W. Schlegel, 1799, p. 177). Así fue como "el rey del romanticismo”, tal y como le coronaron sus coetáneos, se encargó de traducir El Quijote y lo hizo, muy curiosamente, empleando como ya se ha señalado, un concepto, Tathandlung, que en ese momento brillaba con especial y fichteana intensidad. Por esa misma época, otra traducción hizo acto de aparición: la de Dietrich Wilhelm Soltau ${ }^{8}$ anunciada por el librero F. Nicolovius en junio de 1799. Las diferencias entre ambas traducciones son muy destacables y allí, por volver a nuestro término clave, donde Tieck vertió "hazaña" como "Tathandlung", Soltau, en cambio, la tradujo a veces como "Unternehmen" y otras como "That", algo así como "empresa (audaz)" y "hecho" respectivamente. ' Aunque el editor hizo el anuncio de la nueva publicación sin ánimo de polémica, ésta no se hizo esperar y Friedrich Schlegel una reseña muy crítica con la de Soltau y muy generosa con la de Tieck, comparando a ambas con la antigua traducción que circulaba por Alemania, la de Bertuch (F. Schlegel 1799, pp. 282-283). Ésta última hacía del Quijote una novela de tono casi caricaturesco que no daba cuenta de la altura del original, hasta el punto de que para Tieck El Quijote de Bertuch no era realmente El Quijote porque no respetaba el alma de la obra (Neumann 2004, p. 92). ${ }^{10}$ Tampoco la de Soltau hacía justicia al espíritu del Quijote porque la tomaba como obra cómica con un claro propósito moralizante, como una parodia de las "insanas" novelas de caballerías de épocas

\footnotetext{
${ }^{8}$ La traducción apareció entre 1800 y 1801 con el título Der sinnreiche Junker Don Quixote von La Mancha. La primera edición se encuentra disponible online < https://opacplus.bsb-muenchen. $\mathrm{de} / \mathrm{metaopac} /$ singleHit.do? methodToCall=showHit\&curPos=5\&identifier=100_SOLR_ SERVER_1189480679>

9 Véase por ejemplo, el empleo de "That" o de "Unternehmen" en la traducción de Soltau en Cervantes 1800-1801, p. 252. <http://reader.digitale-sammlungen.de/resolve/display/ bsb10607217.html>

${ }^{10}$ Correspondencia de Tieck a A.W. Schlegel 23 diciembre 1797. Sobre esta lectura equivocada, que hace del Quijote una sátira, dice Schelling en 1802-1803: "Sería igualmente necio, o más necio aún, rebajar las comedias de Aristófanes a la especie de la sátira y, como solía hacerse, convertir en una sátira el Don Quijote de Cervantes". SW I/5, 667; trad. de Virginia López Domínguez en Schelling, F.W.J. (1999): Filosofía del arte, Madrid: Tecnos, p. 407.
} 
pasadas. Todo lo que no contribuyera a esta línea argumental podía pasar sin ser traducido por irrelevante. Sólo la de Ludwig Tieck hacía del hidalgo un paladín del idealismo y de Sancho un personaje profundo que hablaba, según A.W. Schlegel, "con gracilidad". ${ }^{11}$ Tieck resaltaba la vertiente irónica y la vertiente poética del Quijote: la obra contenía de este modo para los románticos la lucha entre lo ideal y lo real, entre el sueño y la vida, entre la realidad y la ficción e, incluso, hacía de toda realidad una ficción en sí misma. Y aún más, constituía un precedente de un tipo de novela (roman $)^{12}$ que desplegaba su argumento al mismo tiempo que se desarrollaba el yo de su protagonista: una Entwicklungsroman integrada en el grupo de la "literatura del Yo" tan característica de la época. ${ }^{13}$ La traducción además debía tratar de verter cada coma por ser El Quijote, según August W. Schlegel, era una expresión de la poesía universal por su mezcla de elementos heterogeneos (A.W. Schlegel 1971-1972, p. 342). Así, mientras que la traducción de Tieck fue defendida por los Románticos, la de Soltau se convirtió en la preferida por los Ilustrados. ${ }^{14}$

En este contexto, la elección del término Tathandlung para traducir hazaña no es tan azarosa o casual como inicialmente pudiera parecer. Tieck estaba interpretando El Quijote según la recepción romántica de Fichte. No deja de ser

${ }^{11}$ Schlegel, A.W. (1799): “Cervantes Saavedra, M. de: Leben und Thaten des scharfsinnigen Edlen Don Quixote von la Mancha. Bd. 1. Übersetzt v. L. Tieck. Berlin: Unger 1799”. En Allgemeine Literatur Zeitung, 230, 20 de julio.

${ }^{12}$ Sobre la relación del concepto de roman con el romanticismo, tanto etimológicamente y como por ser la forma privilegiada por el Romanticismo recuérdese la afirmación de F. Schlegel en "Carta sobre la novela" incluído en su Diálogo sobre la poesía (1800): "Ein Roman ist ein romantisches Buch". Los dos grandes autores de referencia serán Cervantes y Shakespeare. Véase "Gespräch über die Poesie", en Schlegel, F. (1958): Kritische Friedrich-Schlegel-Ausgabe (KFSA), ed. E. Behler, München/Paderborn: Schöningh, vol. II, p. 335. Hay traducción al castellano Schlegel, F. (1994): Diálogo sobre la poesía, Madrid: Alianza editorial, pp. 129-138. Fue Jean Paul quien popularizó el uso de los términos "romanticismo" (Romantik) y "romántico" (der Romantiker). Cfr. Pikulik, L. (2000): Frühromantik. Epoche - Werke - Wirkung, München: Beck.

${ }^{13}$ El Werther de Goethe (1774), Lucinde de Schlegel (1799), William Lovell de Tieck (1795-1796) serían ejemplos de este tipo de literatura caracterizada por la introspección romántica de la subjetividad. Cfr. Argullol, R. (1990): El héroe y el único, Barcelona: Destino, p. 36.

${ }^{14}$ Sobre la polémica cfr. Strosetzk, C. (2005): Miguel Cervantes Don Quijote: Explizite und implizite Diskurse im Don Quijote, Berlin: Erich Schmidt Verlag; García Albero, J. (2013): “El 'Quijote': una de las grandes querellas traductológicas”. En Mata Induráin, C.- Sáez, A. J. - Zúñiga Lacruz, A.: (eds.), «Festina lente». Actas del II Congreso Internacional Jóvenes Investigadores Siglo de Oro (JISO 2012), Pamplona: Servicio de Publicaciones de la Universidad de Navarra, pp. 193-204. 
curioso en este punto cómo el Rey del Romanticismo hizo suyos algunos de los planteamientos del "Titán de Jena" (según el apelativo que le dio, de forma no muy inocente, Jean-Paul Richter a Fichte ${ }^{15}$ ) que si bien no fue rey del Idealismo, sí puede considerarse, aunque muy lejos de la lectura propalada por el propio Hegel en sus Lecciones sobre la historia de la filosofía, su iniciador. De esta forma, Tieck estaba "romantizando" a Fichte, el primer Fichte, a través del Quijote, de ahí que de su traducción se desprenda una compresión del autor de la Doctrina de la Ciencia "romantizada" que puede rastrearse también en otras obras. Esta relación inicial entre el círculo de la Frühromantik y la primera formulación de lo que será el gran movimiento idealista, no deja de resultar interesante dada la aparente oposición que siempre se ha defendido a la hora de analizar dos movimientos que ocupaban un mismo tiempo y un mismo espacio, que se entrelazan y convergen ahora a través de dos de sus grandes figuras: Tieck y Fichte. Ahora bien ¿qué tomó el Rey del Romanticismo del Titán de Jena? ¿cómo interpretó el romanticismo la Doctrina de la Ciencia?

La filosofía fichteana se fundamentaba, como afirmaba Cohen en la anécdota que recuperábamos al principio, en torno al concepto de Tathandlung, término traducido a veces como "acción originaria" (trad. de J.L. Villacañas y M. Ramos en Fichte 1978) y otras como "acción de hecho" (Duque 1998, p. 209) para tratar de reflejar el sentido de un concepto ideado por el propio Fichte para referirse a un nuevo principio de la filosofía - propuesto por él_ que no era un simple hecho (Tatsache), sino una instancia autodeterminante, fundada en un verdadero querer. Como bien se sabe, el germen del término puede rastrearse ya en 1793 en la reseña a Creuzer publicada en la Jenaer Allgemeine Literatur-Zeitung ${ }^{16}$ para ser explicitado poco después en la reseña del Aenesidemus de Schulze. Mientras que la Tatsache de

\footnotetext{
${ }^{15}$ El apelativo de "titán" se incluye en un manifiesto cómico que Jean Paul escribió contra el pensamiento de Fichte, la Clavis fichteana seu Leibegeberiana, publicada en 1800 pero escrita durante el periodo de la polémica sobre el ateísmo, ya mencionada. Cfr. Jean-Paul (1980): Werke, ed. N. Miller, München: Carl Hanser, pp. 1011-1056. Puede profundizarse en la relación Jean-Paul Fichte la monografía de Harich, W. (1968): Jean Pauls Kritik des philosophischen Egoismus, Frankfurt a.M.: Suhrkamp; Hesse, S. (2005): “"Mir (empirisch genommen) grauset vor mir (absolut genommen).": zur philosophischen Kritik und poetologischen Reflexion in Jean Pauls "Clavis Fichteana"», en Jabrbuch der Jean-Paul-Gesellschaft, 40, pp. 107-149.

16 Cfr. Serrano, V.: "Un paso en el lento ascenso hacia la Doctrina de la ciencia. Introducción a J. G. Fichte, Reseña de Creuzer”. En Revista de Estud(i)os sobre Fichte [En línea], 9 | 2014, Publicado el 28 diciembre 2014, consultado el 1 de septiembre de 2015.

URL: < http://ref.revues.org/564 >
} 
Reinhold (de Tat, hecho y Sache, cosa), reducía la realidad a un compuesto de cosas hechas y hacía del fundamento un mero hecho de conciencia (Hartman 1960, p. 68.), la Tathandlung aludía a la acción, al obrar en sí mismo (Handlung) aparejado a todo hecho (Tat) que es resultado de aquel, es decir, que el Yo no es un hecho, sino una actividad y una actividad libre. No un "yo soy" o un "yo pienso" cartesiano, sino un "yo actúo": la conciencia es, por ello, activa, eminentemente práctica, pero no sólo porque actúe sino porque se hace a sí mismo, se "pone" en el acto mismo del obrar. Respondía así Fichte al desafío lanzado por Reinhold para el cual era preciso encontrar un fundamento que la filosofía kantiana no tenía si es que ésta quería ser entendida de forma sistemática. La Tathandlung consistía de este modo en la acción reflexiva por la cual y en la cual se produce el hecho de la conciencia o, por decirlo con el propio Fichte, en "una actividad pura, que no presupone un objeto, sino que lo produce ella misma, y donde por tanto el actuar (Handeln) se convierte en un hecho (Tat)" (GA I/4, 221).

El despliegue de la Doctrina de la Ciencia constituye un camino que coincide con las fases de un movimiento reflexivo por parte del sujeto, mediante el cual el Yo toma conciencia de sí mismo y del mundo. Y como camino no es, desde luego, un ciencia en sí misma, sino una propedéutica que indica cómo es posible la ciencia al interrogarse por las condiciones de posibilidad del conocimiento íntimamente ligadas a la actividad práctica. De hecho, en el parágrafo 8 del opúsculo programático Sobre el concepto de la Doctrina de la Ciencia (1794) el propio Fichte subraya los dos aspectos que constituyen su propuesta y que están íntimamente relacionados: la parte teórica que, como bien se sabe, tiene como tarea la deducción de la representación (explicar el Yo y el mundo) y que constituye un proceso genético-deductivo en el que las sucesivas fases o "categorías" son deducidas unas a partir de otras; y la segunda parte, la práctica, que es la clave de bóveda (Scblusstein por recordar la formulación kantiana en Ak. V, p. 3) de todo el sistema fichteano, consagrada a la transformación en sí misma de la realidad según las exigencias originarias del Yo articuladas en torno a una conciencia moral. Dicho de otro modo: el mundo no es como debería y, por ello, el Yo debe actuar desde sí y transformar el mundo. Del ser al deber ser. Desde este punto de vista el mundo es mero material (Stoff) que ha de ser conformado (bilden) por el Yo para su elaboración. Pero nada es tan fácil como "ponerse manos a la obra", puesto que para proceder a transformar algo es preciso que el Yo sienta una oposición o una resistencia que le permita no sólo ser consciente de tu propio Yo como actividad, sino incluso dar forma a su obrar: si no sería una actividad que se perdería en el infinito, sin ningún contrario, como si un escultor — permítaseme 
el ejemplo- hundiera sus manos en un material tan poco consistente que, suelto entre sus dedos, no le permitiera ejecutar su trabajo. Por eso si según Fichte el primer principio de la Grundlage, "El Yo pone originariamente, sin más, su propio ser" ("Das Ich setżt ursprünglich schlechthin sein eignes Sein") (GA I/2, 261) tiene que ver con una autointuición del Yo, es decir, con la conciencia de sí que tiene el Yo a través de una intuición intelectual al poner algo (GA I/2, 135, 151) $)^{17}$, el segundo principio surge de la necesidad de una contraposición. Si el Yo fuera lo único que hay, se perdería en la infinitud de la actividad que él és, luego si puede ser distinguido es que puede serlo con respecto a otra cosa: algo que no es él y que se le opone y que le ofrece una necesaria resistencia: el No-Yo. El segundo principio tiene que ver por lo dicho con un segundo poner del Yo puesto que para saber de sí como Yo debe salir de sí mismo (GA I/2, 408-409): "Al Yo se contrapone absolutamente un No-Yo" ("Dem Ich wird schlechthin ein Nicht-Ich entgegengesetzt?") (GA I/2, 266).

$\mathrm{La}$ actividad ha de encontrar una resistencia para hacer reflexionar al Yo sobre sí, hacerse cargo de sí mismo y de sus momentos constitutivos volviendo o regresando (zurückgehen) sobre sí. Si mediante la Tathandlung el Yo se había mostrado como actividad libre, espontánea y originaria por la que se "pone" a sí mismo, con esta segunda acción de retorno sobre sí se explicita su reflexividad característica, su autoconciencia como "ser para sî" al mismo tiempo que "pone" el mundo, intrínsecamente vinculado así al propio Yo. Al segundo principio, le sigue un tercero: "En el Yo contrapongo al Yo divisible un No-Yo divisible" (GA I/2, 270-271) por el que se justifica el mundo de la experiencia, de los hechos, que lleva implícito un proceso de "construcción racional" y de transformación de la realidad íntimamente ligada a la parte práctica: "Debo partir del Yo puro en mi pensar, y pensarlo como absolutamente activo desde sí mismo, no como determinado por las cosas, sino como determinando las cosas" (GA I/4, 219-220). En este movimiento de despliegue de la conciencia a través de la deducción, la actividad del Yo ha de caracterizarse por una aspiración o esfuerzo (Streben) por la que el Yo aspira a la plena realización, aunque ésta realización sea por sí misma imposible por infinita, y reside en un deber y no en un ser. El Yo, en lucha, combate o duelo, con el No-Yo, busca transformarlo en lo que debe ser. Así el Yo se enfrenta, porque debe enfrentarse, a sucesivas resistencias (Widerstände), literalmente lo que se levanta (stand del al. stehen) contra él (wider-)... como se levantaban en el horizonte contra el Quijote los gigantes puestos (gesetz̨) por él mismo, fruto de

${ }^{17}$ Cfr. GA II/ 6, 172. 
su imaginación (Einbildungskraft), puesto que no eran gigantes, sino molinos. Las hazañas del Yo en Fichte consisten, justamente, en vencer las obstáculos y hacerlo por deber, como bien vemos en la Sittenlehre o Sistema de la doctrina de las costumbres según los principios de la Doctrina de la Ciencia, publicada en nuestra Jena de 1798. Pero además debe hacerlo en un mundo, el suyo, que no es sino el sentido materializado del deber. Hasta aquí, Fichte.

La pregunta se desplaza ahora al sentido que los románticos vieron en las hazañas descritas en el Quijote, como si su odisea, sus aventuras, algo tuvieran en común en el despliegue que ha de llevar a cabo el Yo en la Doctrina de la Ciencia. Lo que caracteriza al Quijote es su voluntad de aventuras, esto es, su voluntad de hechos heroicos que sólo pueden alcanzarse a través de la realización de grandes hazañas. Ahora bien, ¿qué es una hazaña? Es un hacer (su origen etimológico la vincula con facio), pero un hacer que "ha requerido mucho valor y esfuerzo" (María Moliner). Una proeza pues: la acción de un héroe. De nuevo, Ortega: "es un hecho que existen hombres decididos a no contentarse con la realidad. Aspiran los tales a que las cosas lleven un curso distinto [...] Estos hombres los llamamos héroes. Porque ser héroe consiste en ser uno, uno mismo" (Ortega y Gasset 2004, p. 286). Si con la filosofía de Fichte la Tathandlung respondía a un nuevo "tipo de filosofía" que tiene que ver con el tipo de hombre que se es, con el Quijote queda claro qué tipo de hombre es éste: uno que no se contenta con el mundo y quiere hacer de él lo que debe ser. Recupera un tiempo heroico en el que no se da por vencido. El Yo, su yo, es un Yo que lucha, que se rebela y que no cede a la sumisión dada por la pasividad. A través de sus hazañas, el Quijote quiere cambiar el mundo. "Yo soy el valeroso D. Quijote de la Mancha — leemos en la obra de Cervantes_-, el desfacedor de agravios y sinrazones" (Cervantes 2005, p. 32). ${ }^{18}$ Su acción es, por ello, eminentemente moral, como lo era la Tathandlung para Fichte y, a través de la Tathandlung, con sus hazañas es como el Quijote deviene él mismo Quijote: se hace a sí mismo, toma conciencia de sí y de quién es como ilustre caballero y, al mismo tiempo, hace de su mundo la materialización de su deber.

Lo que al hidalgo le importa son las hazañas y ser recordado por las mismas: su vida o, si se quiere, su odisea consiste justamente en enfrentarse con dificultades, esto es, con resistencias, a lo largo de las diferentes aventuras que harán de él un

${ }^{18}$ En la traducción de Tieck, Cfr. Cervantes, M. (1799-1801): Leben und Taten des scharfsinnigen Edlen Don Quixote von la Mancha, J. F. Unger, Berlin, 1799-1801, vol. I, primera parte, capítulo IV, p. 40. Disponible online <http://reader.digitale-sammlungen.de/de/fs1/object/display/ bsb10608638_00005.html> [consultado el 1 de septiembre de 2015] 
héroe y conformarán su fama. Así libera el Quijote al joven pastor que es apaleado por su amo en la primera de las salidas narradas en la novela o, acompañado por el juicioso Sancho, trata de derrotar a los gigantes que salen a su paso — gigantes que él mismo ha puesto como se apuntaba anteriormente- o se enfrenta en duelo al bachiller Sansón Carrasco, que es "puesto" (o considerado) por el hidalgo como el Caballero de la Blanca Luna. Y nótese bien: Sansón Carrasco ha de transformarse en el personaje imaginado por el Quijote para poder ser integrado en su mundo y lograr vencerlo como rival. Su Yo mismo consiste en esto: "Yo soy aquel para quien están guardados los peligros, las grandes hazañas, los valerosos hechos" (Cervantes 2005, 104) o, en la traducción de Tieck: "Ich bin es, dem Gefahren, große Thathandlungen, mächtiges Unterfangen aufbewahrt sind" (Cervantes 17991801, p. 278). ${ }^{19}$ La hazaña que los Románticos ven en el Quijote es la acción misma que lleva a ser un héroe: a realizar actos heroicos y, al hacerlos, devenir él mismo haciéndose cargo de si mismo y del mundo, porque en él reinan las injusticias y los agravios. Su historia es, por tanto, la historia también de su toma de conciencia en su lucha contra las resistencias. Toda una odisea.

\section{EL PROYECTO DEL QUIJOTE}

La hazaña en sí misma está movida por una conciencia del deber, en la que lo que importa es, sobre todo, el esfuerzo y la intención. Su valor recae en ella misma y en lo que con ella se consigue: transformar el mundo. El Quijote hace lo que cree que debe hacer, lo que su conciencia moral le dicta. Su mundo es el resultado del sentido materizalizado del deber, y, justamente por ello, necesita de un caballero andante que transforme la realidad. Tal tarea se realiza recuperando los viejos tiempos de las caballerías a través de su imaginación. Volviendo a Fichte, en el final de la parte teórica debía llegarse a la conciencia real a través de la transformación de las condiciones de posibilidad en condiciones de realidad gracias a la importante función de la imaginación (Einbildungskraft), que media entre la intuición y el concepto puro. El Quijote sigue pues un ideal o, si se quiere, una imagen (Bild): podríamos decir que el proyecto, esto es, el prototipo ulterior

${ }^{19}$ En la traducción ilustrada de Soltau encontramos el empleo de "Unternehmen" y "That". Ni rastro de la Tathandlung: "Mir ist es beschieden, durch gefährliche Unternehmungen, durch große und tapfere Thaten mich berühmt zu machen". Cursiva nuestra. En Cervantes, M. (1800-1801): Der sinnreiche Junker Don Quixote von La Mancha, op. cit. primera parte, capítulo XX, p. 330. Disponible online: <http://reader.digitale-sammlungen.de/de/fs1/object/display/ bsb10608638_00005.html> [consultado el 1 de septiembre de 2015] 
de todo hecho que sigue del obrar del Yo de Don Quijote o del intentar obrar, consiste en el programa heroico dado por los modelos que Alonso Quijano ha tomado de sus lecturas de los libros de caballerías: y este proyecto es la imagen (Vorbild), fundamento de la actividad del Yo, que el Yo anhela (sehnen) hacer efectivamente "real" y que constituye su impulso a la acción (Trieb). La realidad de Don Quijote es la copia (Nachbild) del modelo de los libros de caballerías (Vorbild) que transforma y mueve a la acción al yo de Don Alonso Quijano. Recuperamos en este punto a Fichte: "Al poner el Yo esta imagen [Bild] como producto de su actividad [Thätigkeit], la contrapone necesariamente a algo que no es producto de esa actividad y que ya no es determinable [bestimmbar], sino que está perfectamente determinado [bestimmt] y, sin intervención ninguna del Yo, determinado por sí mismo. Ésta es la cosa efectiva [wirkliche], la guía del Yo configurador [bildende] cuando éste proyecta su imagen, y que debe cernirse para él, pues, necesariamente, con ocasión de esa imagen" (Fichte 1795, pp. 59-60). El Yo se enfrenta así a lo determinado. Tenemos pues, en este punto, uno de los grandes temas de la filosofía de Fichte (sobre todo a partir de 1804 y 1805) y del romanticismo: el de la imagen (Bild), asociada a la idea del cierre perfecto, a la imposible consumación de la transformación del mundo en lo que debe ser, y el de su conexión con el anhelo (Sebnen) para que así sea.

La imaginación (Einbildungskeraft) en Fichte es la que produce toda realidad: del mismo modo que el Quijote produce su realidad mediante su imaginación, viendo, en primer lugar, lo que quiere ver para poder "ser un héroe" en un tiempo que ya no los tiene, como en el caso de los "gigantes" y, más allá de eso, en segundo lugar, con el intento de transformación del mundo para "mejorarlo" llevado por la conciencia del deber, el Yo de Fichte no hace sino producir su realidad. Por eso Albert Béguin en las páginas que dedica a Tieck en El alma romántica y el sueño recoge esta afirmación: "Todo cuanto nos rodea solo es verdadero hasta cierto punto" (Béguin 1993, p. 271), no porque todo sea falso, sino porque esa realidad exterior está relacionada con el yo interior y no hay, por ello, un mundo puramente "objetivo"que podamos conocer. El mundo es ya el Yo y el Yo es ya su mundo. Y ¿acaso uno de los grandes temas del Quijote no es justamente la oposición entre realidad y ficción?

El concepto de imagen (Bild) tiene una función fundamental en la propuesta fichteana porque implica un proceso de formación (bilden) que explica el tercero de los principios de la Wissenschaftlehre: la imagen, el conocimiento si se quiere, no es una representación de un mundo exterior previo, sino que tiene que ver con la capacidad imaginativa del sujeto a través del cual hay un modelo más allá de 
lo empírico que posibilita entender el conocer en sí mismo y que responde a la perspectiva trascendental por al cual el conocimiento precede al ser (Asmuth 2011). La concepción de la imaginación en Fichte influyó decisivamente en los románticos: así, por ejemplo, para Novalis cuando la imaginación produce la materia para el arte, ella produce una realidad con un contenido de verdad superior. El Quijote, al igual que el Yo, tiene una imagen — un proyecto— del mundo: "en esa acción de la imaginación — dice Fichte — se funda la posibilidad de nuestra conciencia, de nuestra vida y de nuestro ser, para nosotros, es decir, de nuestro ser en cuanto Yo" (GA I/2, 368). Una ficción que, aunque sea "imaginada" es, sin embargo, necesaria: "sin una bienhechora ilusión de la imaginación $[. .$.$] no habríamos$ podido emprender las investigaciones presentes; no habríamos podido pensarlas [...] Esta ilusión no podría ser evitada y no debía serlo" (GA I/2, 365). Sueña el Quijote como imagina el Yo, y eliminada la ilusión (Traumbild) de la imaginación, no queda nada: ni siquiera el Yo... tampoco el Yo de Alonso Quijano que, cuando todos sus libros, que le proporcionaban "imágenes" (Bilder) para la producción de su imaginación, son quemados, "recobra la cordura" y muere, pero con él muere a su vez todo un mundo. En este momento, Sancho, su escudero, toma el relevo y así le dice: "Mire no sea perezoso, sino levántese de esa cama, y vámonos al campo vestidos de pastores, como tenemos concertado" (Cervantes 2005, p. 671). Según la traducción de Tieck "Seid doch nicht so lässig, sondern steht aus dem Bette auf, und wir wollen uns auf das Feld begeben, als Schäfer angezogen" (Cervantes 1799-1801, vol. 4, p. 541). El cese de la actividad, el abandonarse, vencido en la cama, sin ninguna imagen que perseguir, significa la muerte del Yo. Pero además, con esta reacción de Sancho, ¿no responde éste a la enseñanza de Fichte en sus lecciones cuando afirma que cada uno de los oyentes debe ser capaz de hacer ese mismo movimiento del Yo, que cada uno debe hacer sus Tathandlungen, de realizar sus hazañas? ¿no debemos cada uno de nosotros, según la Doctrina de la Ciencia, recorrer a su vez el camino emprendido por el maestro y salir, de nuevo, al campo a batallar? Así lo indica Fichte: quien quiera comprender su sistema ha de acometer el mismo ejercicio que él realiza, seguirle en el proceso de su reflexión: "quien no piense con él [con el maestro] no obtendrá nada; sólo el que piensa puede obtener provecho” (GA IV/3, 329).

\section{El No-Yo DEL YO Y LA DESFUNDAMENTACIÓN DEL MUNDO}

Tieck no fue, sin embargo, un fichteano, aunque tuviera en cuenta su filosofía. Amigo muy próximo de quien fuera compañero de viaje de Schelling en el despliegue 
de la Naturphilosophie, Henrich Steffens, su pensamiento estaba más orientado a penetrar en lo que fuera la naturaleza, pero una naturaleza indomeñable que ya no se sitúa como un contrario al Yo que le da su sentido (como un No-Yo), sino que, antes bien, implica la afirmación de una naturaleza en nosotros mucho más oscura e ingobernable de lo que quisiéramos aceptar y que implica la aceptación de un No-Yo dentro del Yo (Ffytche, 2012 y Carrasco Conde, 2015). De este modo, su preocupación por la estructura de la conciencia del sujeto y su comprensión de la realidad, hacen que las reflexiones sucesivas del Yo que veíamos en relación con la Tathandlung de Quijote no puedan sino acabar en un teatro de espejos, en las mil capas de una muñeca rusa: "siempre hay una obra dentro de otra" exclama el personaje del Pierrot en la pieza Die verkehrte Welt (1798). En esa misma línea en el Phantasus (1812-1816), Tieck mencionará el movimiento circular (Zirkellinie) de la conciencia que no conduce a nada "salvo de vuelta, a sí misma".

Tieck no puede compartir la fichteana idea de que Yo puede transformar el mundo, sino que con los Naturphilosophen, cree que hay un mundo en cada Yo. Debe entenderse con esto que si el Yo es el que ponía el mundo, ahora el mundo pondrá al Yo en su lugar. El mundo así ya no será comprensible para el Yo, perdido en un juego de ficciones y velos que ocultan lo que subyace tras la apariencia de orden y control. Antes de caer en el total desfondamiento de toda la realidad y poco antes a las fechas de traducción del Quijote, en 1797 Tieck había publicado una colección de cuentos en tres volúmenes: Volksmärchen (1797), que incluía además del conocido Gestiefelten Kater ("El gato con botas"), el considerado por Dilthey el más perfecto cuento del Romanticismo alemán: Der blonde Eckbert ("Eckbert, el rubio") que si bien no contiene términos fichteanos, sí refleja elementos derivados del contenido de la Grundlage que, por aquel entonces, eclipsaba toda la filosofía alemana. Eckbert, el rubio es la historia de una siniestra toma de conciencia del Yo. Como señala Béguin, los personajes de Tieck se caracterizan por hacer del mundo exterior una proyección desde su interior (Béguin 1993, p. 271), de ahí las continuas alusiones a la infancia y que, le llevarán finalmente, como en Der Runenberg (1802) a tomar el camino de la Naturphilosophie. Der Runenberg comienza con la imagen de un cazador que sobre la cima de una montaña, mira el horizonte del mundo que cree suyo. Considera que todo cuanto la vista alcanza es su patria y su dominio (Tieck 1987, 19): “Tomé posesión de la región en la que me encontraba como si fuera el rey de ella, aprendí de memoria todas las rocas y todas las hendiduras de la montaña” (Ibid, 22). Pero siente sin porqué melancolía y dolor por su soledad. El yo parece estar solo consigo mismo. Tras arrancar una brizna de hierba, escucha una queja subterránea (Ibid, 20). Pronto verá este cazador que él no es más que 
un elemento más de esa naturaleza que creía dominar. La cima de esa montaña, el Runenberg, se encuentra horadada de minas, cuevas y profundidades, como una cara nocturna y escondida que podrá conocer jamás y que le acabará dominando a él: "Llegó hasta un lugar donde no había estado nunca: las peñas eran muy escarpadas, lo verde desaparecía, las laderas peladas parecían llamarle con voces atronadoras y un viento solitario y quejumbroso le azotaba [...] No prestó atención a las profundidades que se abrían ante él como si amenazasen con tragarle" (Ibid, 23-24). Engañado por la creencia de la superioridad de la razón, ve lo que quiere ver, lo que él mismo proyecta. Pone su mundo, como aquel Yo fichteano, pero un mundo que no es otra cosa que una ficción. Todo cuanto nos rodea para Tieck sólo será verdadero hasta cierto punto (Béguin 1993, 271). Más allá del mundo que el Yo cree poner se encuentra algo más profundo. Ir más allá de la linea que separa la zona diurna de la razón, como hace Christian, el personaje principal de Der Runenberg al desoir los dictámenes de la razón y decidir profundizar en la montaña, conlleva el peligro de la pérdida en sí mismo, de lo inconsciente, de la imposibilidad de volver atrás cuando la conciencia se interna en el lado nocturno. Otro personaje, seducido por la montaña, "se levantaba como dormido y paseaba por el cuarto inconsciente, y refería cosas tan raras que daban horror" (Ibid, 31).

Lo que contienen las obras de Tieck es siempre un doble movimiento por el que "Nuestra vida consiste en un doble esfuerzo: descender hasta el fondo de nosotros, y luego, olvidándonos, salir de nosotros mismos" (citado por Béguin 1993, p. 275), pero en Tieck el Yo en su soledad —y ya sabemos que para Fichte el Yo siempre está con lo otro de sí- produce una vuelta de tuerca a la reflexividad del Yo: si, como dirá Fichte en la WLnm- K (1798): "El yo es lo que se pone a sí mismo, y nada más, y lo que se pone a sí mismo y retorna a sí, se convierte en un yo, y nada más. Actividad que vuelve a sí y yo, son una y la misma cosa, ambas se coimplican agotándose mutuamente" (GA IV/3, 345), en Tieck ese retorno implica la irrupción de una imagen y de un conocimiento hasta el momento escondido, que desajusta al Yo y lo desfonda: lejos de devenir sí mismo, el Yo pierde el sentido de lo que es, no ante la falta de conocimiento, sino ante la radicalidad del mismo, y lejos de producir una realidad, se da cuenta de que está perdido en un laberinto compuesto por multitud de realidades calidoscopicas tal y como sucede en El rubio Eckbert. la acción de hecho genera un laberinto para la conciencia y con ella se abre un acceso a la naturaleza que se encuentra dentro mismo del Yo. Lo mismo sucede en Der Runenberg: "trató de reflexionar y encadenar sus recuerdos, pero su memoria parecía envuelta en un cental de niebla tras el cual figuras informes movíanse de un modo extraño y apenas visible. Toda su vida yacía como en una 
profunda lejanía; lo raro y lo vulgar estaban tan entretejidos que era imposible separarlos" (Tieck 1987, 25-26). El Yo, alberga de este modo, otras figuras de la conciencia no relacionadas con el desarrollo de su conciencia, sino, justamente, con el proceso de su desfondamiento.

\author{
Ana Carrasco Conde \\ Universidad Complutense de Madrid \\ anacconde@ucm.es
}

\title{
BIBLIOGRAFÍA
}

Argullol, R. (1990): El héroe y el único, Barcelona: Destino.

Asmuth, C. (2011): Bilder über Bilder - Bilder obne Bilde. Eine nene Theorie der Bildlichkeit,

Darmstadt: Wissenschaftliche Buchgesellschaft.

BÉGUIN, A. (1993): El alma romántica y el sueño, Madrid: Fondo de Cultura Económica.

CARRASCO CONDE (2015): "El sueño magnético: Schelling, Schubert y el mesmerismo.

Glosas a las Edades del mundo (1813) - WA II, 159-168”. En Hay, K., Carrasco

Conde, A.: Génesis Deseo Tiempo. Comentario a las Edades del mundo 1813, Digital magazinephilosopby@lisbon.

CERvanteS, M. (1799-1801): Leben und Taten desscharfsinnigen Edlen Don Quixote von la Mancha, J. F. Unger, Berlin, 1799-1801, 4 vols. Trad. de L. Tieck. URL = http://reader.digitalesammlungen.de/de/fs1/object/display/bsb10608638_00005.html. Consultado septiembre 2015.

- (1800-1801): Der sinnreiche Junker Don Quixote von La Mancha, Königsberg: Nicolovius. Trad. de Dietrich Wilhelm Soltau. URL = https://opacplus.bsb-muenchen.de/metaopac/ singleHit.do?methodToCall=showHit\&curPos=5\&identifier=100_SOLR_ SERVER_1189480679. Consultado septiembre 2015.

- (2005): El ingenioso bidalgo Don Quijote de La Mancha, Madrid: Espasa Calpe.

DANTON, G. H. (1907): The Nature sense in the writing of Ludwig Tieck, Nueva York: Columbia University.

DuQue, F. (1998): Historia de la filosofía moderna, Madrid: Akal.

FFYTCHE, M. (2012): The Foundation of the Unconscious. Schelling, Freud and the Birth of the Modern Psyche, Cambridge.

Fichte, J. G. (1970): Gesamtausgabe der Bayerische Akademie der Wissenschaften (GA), ed.

R. Lauth, H. Jacob y H. Gliwitzky, Stuttgart: Frommann-holzboog, 1970.

- (1795): Grundriss des Eigenthümlichen der Wissenschaftslehre; Jena \& Leipzig: Gabler.

- (1978): Doctrina de la ciencia nova methodo, Valencia: Natan. Trad. de J.L. Villacañas y

M. Ramos. 
FuCHS, E. (ed.) (1980): Fichte im Gespräch, Stuttgart-Bad Cannstatt: Frommann-holzboog. García Albero, J. (2013): “El 'Quijote’: una de las grandes querellas traductológicas”. En Mata Induráin, C.- Sáez, A. J. - Zúñiga Lacruz, A.: (eds.), «Festina lente». Actas del II Congreso Internacional Jóvenes Investigadores Siglo de Oro (JISO 2012), Pamplona: Servicio de Publicaciones de la Universidad de Navarra, pp. 193-204.

GOde-VON AEsch, A. (1947): El Romanticismo alemán y las ciencias naturales, Madrid: Espasa-Calpe.

GüRZEL, K. (1986): König der Romantik: das Leben des Dichters Ludwig Tieck in Briefen, Selbstzengnissen und Berichten, Berlin: Wunderlich.

HARICH, W. (1968): Jean Pauls Kritik des philosophischen Egoismus, Frankfurt a.M.: Suhrkamp. HARTMAN, N. (1960): La filosofía del idealismo alemán, Buenos Aires: Editorial Sudamericana. Hesse, S. (2005): “"Mir (empirisch genommen) grauset vor mir (absolut genommen)”: zur philosophischen Kritik und poetologischen Reflexion in Jean Pauls "Clavis Fichteana"», en Jabrbuch der Jean-Paul-Gesellschaft, 40, pp. 107-149.

Hölderlin, F. (1990): Correspondencia completa, trad. De H. Cortés y A. Leyte, Madrid: Hiperion.

JeAn-PAul (1980): Werke, ed. N. Miller, München: Carl Hanser.

KodAlLE, K.-M. (1999): Fichtes Entlassung: der Atheismusstreit vor 200 Jabren, Würzburg: Königshausen\&Neumann.

KÖPKE, R. (ed.) (1855): Ludwig Tieck. Erinnerungen aus dem Leben des Dichters nach dessen mündlichen und schriftlichen Mitteilungen, vol. II, Leipzig: Brockhaus.

MARKERT, H. (ed.) (2004): Ludwig Tieck (1773-1853): "lasst uns, da es uns vergönnt ist, vernünftig seyn!”, Berna: Peter Lang.

Neumann, T. (comp.) (2004): "Die schöne Geselligkeit kostet gar keine Zeit”. Geselliges Leben um 1800, Erfurt: Landeszentrale für politische Bildung Thüringen, 2004.

Novalis (1975): Schriften, vol. 4. Tagebücher, Briefwechsel, Zeitgenössische Zeugnisse. Hg. v. Richard Samuel in Zusammenarbeit mit Hans-Joachim Mähl y Gerhard Schulz, Stuttgart, 1975, pp. 274-276.

ORTEGA Y GASSET, J. (1983): "Meditaciones del Escorial". En Obras completas, vol. 2, Madrid: Alianza Editorial/Revista de Occidente.

- (2004): Meditaciones del Quijote, Madrid: Biblioteca Nueva, 2004.

PAulin, R. (1982): A literary biography, Oxford: Clarendon Press.

PIKUliK, L. (2000): Frübromantik. Epoche - Werke - Wirkung, München: Beck.

RADRIZZANI, I. (1996): “Génese de l'esthétique romantique: De la pensée transcendentale de Fichte à la poésie transcendentale de Schlegel” en Revue de Métaphysique et de morale, $\mathrm{n}^{\circ} 4$, pp. 471-498.

Rivera de Rosales, J. y CubO, O. (eds.) (2009): La polémica sobre el ateísmo. Fichte y su época, Madrid: Dykinson. 
SCHLEGEL, A.W. (1799): “Cervantes Saavedra, M. de: Leben und Thaten des scharfsinnigen Edlen Don Quixote von la Mancha. Bd. 1. Übersetzt v. L. Tieck. Berlin: Unger 1799”. En Allgemeine Literatur Zeitung, 230, 20 de julio. URL http://zs.thulb.unijena.de/rsc/viewer/jportal_derivate_00049438/ALZ_1799_Bd.3+4_046_A2.tif. Consultado septiembre 2015.

SCHLEGEL, A.W. (1971-1972): Sämtliche Werke, vol I, ed. por Böckling, Hildesheim / New York.

SCHLEGEL, F. (1799): "Tiecks Übersetzung des Don Quixote von Cervantes". En Athenäum. Eine Zeitschrift von August Wilhelm Schlegel und Friedrich Schlegel, II. En Schlegel, F.: KFSA, vol. 2, pp. 282-283.

- (1958): Diálogo sobre la poesía KFSA, En Kritische Friedrich-Schlegel-Ausgabe (KFSA), ed. E. Behler, München/Paderborn: Schöningh.

- (1967): "Athenaeums-Fragmente". En Kritische Friedrich-Schlegel-Ausgabe (FFSA), ed. E.

Behler, München/Paderborn: Schöningh.

- (1994): Diálogo sobre la poesía, Madrid: Alianza editorial.

SERrano, V. (2014): "Un paso en el lento ascenso hacia la Doctrina de la ciencia.

Introducción a J. G. Fichte, Reseña de Creuzer”. En Revista de Estud(i)os sobre Fichte

[En línea], 9. URL = http://ref.revues.org/564 . Consultado en septiembre 2015.

STRosetzK, C. (2005): Miguel Cervantes Don Quijote: Explizite und implizite Diskurse im Don Quijote, Berlin: Erich Schmidt Verlag.

TIECK, L. (1997): El Runenberg seguido de El rubio Eckbert, Barcelona: Olañeta.

ZEYDEL, E.H. (1971): Ludwig Tieck, the German Romanticist. A critical study, New York: Georg Olms Verlag. 